\title{
LOS ÁNGELES Y LOS ARCÁNGELES DE LA CAPILLA DE SAN MIGUEL DE LA CATEDRAL DE JAÉN
}

\author{
POR JOSÉ FERNÁNDEZ LÓPEZ
}

Este artículo presenta la serie de ángeles y arcángeles que decoran la capilla de San Miguel de la Catedral de Jaén. Se trata de un conjunto de diez lienzos, de interés artístico e iconográfico, pertenecientes a la escuela sevillana de mediados del siglo XVII, con gran influencia zurbaranesca.

This paper presents the set of angels and archangels which decorate the Saint Michael's capell of the Cathedral of Jaén. It deal with ten canvas of artist and iconographical interest, belonging to the sevillian school of the middles XVII century, with a great influence from Zurbarán.

En la capilla de San Miguel de la catedral de Jaén se conserva un conjunto de diez lienzos de mediados del siglo XVII que representa a Ángeles y Arcángeles, piezas todas de buena calidad artística, pertenecientes a la escuela sevillana, y de curiosa y esclarecedora iconografía para el estudio, especialmente, de las series arcangélicas '.

La capilla de San Miguel presenta una decoración barroca muy suntuosa, finalizada en 1761, según reza la inscripción que figura sobre una de las puertas de la cabecera: "ANNO DOM MDCCLXI" ${ }^{2}$. En la profusa ornamentación de la estructura decorativa lígnea, dorada y policromada que inunda las paredes de este espacio, destaca su carácter de marco para contener una rica decoración pictórica en la que, a simple vista por su tamaño, sobresale el lienzo oval del testero, dedicado

1. Óleos sobre lienzos, $193 \times 109 \mathrm{cms}$.

2. Galera Andreu, Pedro, Catálogo monumental de la ciudad de Jaén y su término, Jaén, 1985, pp. 96 y 96; Ortega Sagrista, R., "Noticias sobre algunas capillas de las catedrales de Baeza y Jaén", en Revista Paisaje, n 105 , pp. 1855-1857. 
al patrón de la capilla y que representa a San Miguel luchando contra los demonios. Esta obra, típica por sus característica técnicas y artísticas del siglo XVIII, ha sido tradicionalmente atribuida al pintor jiennense Francisco de Pancorbo. Recientemente se ha encontrado la firma de este lienzo que lo vincula con el pintor sevillano Bernardo Lorente Germán, en el año $1757^{3}$. Se trata de un trabajo de mediano interés, al igual que las pinturas que figuran en el medio punto superior y en las bóvedas, estas de diferente mano. Ese interés se acrecienta ante la presencia de la serie de ángeles y arcángeles ya citada y ubicada en los testeros laterales, en ricos marcos. Estos lienzos se distribuyen en número de cinco en ambos lados $\mathrm{y}$, de principio, hemos de indicar que carecen de una ordenación iconográfica clara, lo que, unido a su datación anterior a la renovación barroca dieciochesca de la capilla, nos hace pensar que se trata de piezas de acarreo o reaprovechadas de la decoración anterior, posiblemente más austera. Tal vez pudiera tratarse también de obras regaladas y ubicadas en este lugar cuando se acometió su renovación.

Esta serie angélica y arcangélica de la catedral jiennense necesita una pronta restauración, dado que su estado de conservación es en general malo y precario en algún caso, observándose suciedades y desprendimientos sobre la superficie pictórica, barnices saturados por el paso del tiempo y distensiones en los lienzos. Sin embargo, su entidad artística es más que suficiente para que la comparemos con los mejores conjuntos arcangélicos conservados de la escuela sevillana de hacia mediados del siglo XVII, como el del Hospital del Pozo Santo, de Sevilla, y el convento de la Concepción de Lima, Perú. Estas series guardan íntima relación iconográfica, con curiosas variantes y claras cercanias artísticas, con la de la catedralicia capilla de San Miguel, aunque las tres de diferente mano.

Comenzando el análisis de estos lienzos, lo realizamos por el testero izquierdo, desde la cabecera, donde, en la parte superior, de izquierda a derecha, aparece en primer lugar un arcángel identificable por sus características iconográficas como Baraquiel. Porta en su mano derecha una corona de flores y en la izquierda una palma. Este arcángel, no canónico, conocido como el "Adjuntor", por ser guía de Moisés y del pueblo de Israel, aparece en los grabados del siglo XVI con un vaso de rosas o con la sobrefalda recogida y llena de flores. El aditamento de la palma es algo típicamente hispano y frecuente en las representaciones sevillanas de mediados del siglo XVII, apareciendo en lienzos en los que no se inscribe el nombre de este arcángel. En similar actitud aparece Baraquiel en la serie del sevillano Hospital del Pozo Santo, con variantes en el modelo, pero con cercanos tratamientos, ricos en lo suntuario y convencionales en el movimiento. La inscripción que figura

3. Aragón Moriana, Arturo, "Noticias en torno a Bernardo Lorente Germán", en Senda de las Huertas, 22, Jaén, 1991, p. 47. Sobre el retablo y documentación de la capilla de San Miguel de be consultarse: Ulierte Vázquez, Ma Luz de, El retablo en Jaén (1580 - 1800), Jaén, 1986, pp. 233-236 y 323-324. Esta autora cree de traza sevillana el retablo. Por su datación y estilo pensamos que no es obra lejana al trabajo de Cayetano de Acosta. 
a sus pies reza: "(Quoniam) Angelis suis mandavit de te ut custodiant te. (Ps. 91, v. 11)"; (Pues) Te encomendará a sus ángeles para que te guarden. (Salmos 91, 11). Esta inscripción, posiblemente no original, como ocurre en buena parte del conjunto, vincula esta imagen a la presencia de un ángel citado en el Antiguo Testamento, en el Libro de los Salmos. Este cambio resulta lógico, dado los problemas que incluso ante el Santo Oficio podría tener la representación de arcángeles que no fuera aceptada por la ortodoxia religiosa ${ }^{4}$. A pesar de ello nos atrevemos a decir que los pintores, al menos los sevillanos del siglo XVII, cuando realizaban estas series no pensaban en crear imágenes alejadas de lo reglado, limitándose a seguir los modelos previos, con variantes iconográficas muy características de los artistas del círculo, seguidores o del obrador zurbaranesco.

Seguidamente encontramos la representación de un Ángel en posición frontal, de bella factura, una de las piezas de mayor calidad y originalidad icongráfica del conjunto. Porta en sus manos una cruz y un cáliz. Estos elementos relacionan esta imagen con el ángel que conforta a Cristo en Getsemaní, quedando confirmado por la inscripción inferior: "Apparuit(autem) illi ang(elus de caelo), confortans eum. (S. Lu. 22, v. 43); Se apareció un ángel del cielo que le confortaba. (San Lucas 22, 43). Esta inscripción, que creemos nuevamente posterior a la ejecución del cuadro, sin embargo, vincula la pintura perfectamente con su iconografía, por lo que la representación puede titularse perfectamente como el Ángel de Getsemani. Esta obra es posiblemente una de las más atractivas del conjunto por su valiente actitud frontal, abierta, el movimiento amplio de los paños, el tratamiento suelto de lo suntuario y la actitud melancólica del personaje, de la que participan en mayor o menor grado todos los que forman la serie.

En el centro de este testero se sitúa la pintura de San Miguel. Al tratarse de un arcángel canónico figura en el ángulo superior izquierdo su nombre: "S. Michael". Se trata de un lienzo cuyo modelo se vincula perfectamente con los habituales y de mejor calidad, en esta representación, en la pintura sevillana de mediados del siglo XVII. Eso ocurre con los San Miguel de la serie Hospital del Pozo Santo, el del retablo de la parroquial de Robledo de Chavela, Madrid, y el del convento de la Concepción de Lima; estos dos últimos de mano muy cercana al de esta serie e incluso similares medidas en los lienzos 5 . Tradicionalmete se viene señalando como modelo de esta representación el Arcángel San Miguel de la colección del Banco Central Hispano

4. Sobre este asunto y otros relacionados con la iconografía de los arcángeles resulta interesante el trabajo de: Sánchez Esteban, Natividad, "Sobre los arcángeles", en Cuadernos de arte e iconografía, t. IV. 8, pp. 91-101.

5. Bemales Ballesteros, Jorge, Catalogo de la Exposición: El siglo de Oro de la Pintura sevillana, Lima, 1985, nros. 49-55; Catálogo de obras restauradas, 1967-68. Sección de pintura ICROA, Madrid 1971, p. 183; Femández López, José, Programas icongráficos de la pintura barroca sevillana del siglo XVII, Sevilla, 1991, p. 147; Stastny, Francisco, "Zurbarán en América Latina", en Zurbarán en los conventos de América, Caracas, 1988; Valdivieso, Enrique., "Ángeles sevillanos en Lima" en Buenavista de Indias, $\mathrm{n}^{\circ} 6,1992$, pp. 35-45. 
Americano, pieza de gran calidad y muy cercana en algunos aspectos al tratamiento pictórico zurbaranesco, aunque se trata de una obra de taller ${ }^{6}$.

En la zona inferior de este testero izquierdo se sitúan de nuevo dos lienzos. En el primero de ellos, a la izquierda, figura la imagen de San Rafael, con una inscripción superior que dice: "(Tunc) Raphael angelus apprehendit daemonium, et regalavit illud (in desert superioris Aegypti). (To. c. 8. v. 3)"; El ángel Rafael apresó al demonio y le ató. (Tobías 8, 3). Esta pintura muestra al arcángel de perfil con ampulosa vestimenta, sosteniendo una columna a la que ató con grilletes al demonio. La zona inferior del lienzo es un añadido. Se trata, por lo tanto, de una iconografía no habitual en la representación de San Rafael. Sí aparece, con ligeras variantes, en la serie arcangélica del Hospital del Pozo Santo en Sevilla, pero con menor calidad, a pesar de los repintes que han afectado a este San Rafael jiennense, hasta el punto, creemos, de hacer desaparecer el brazo derecho. Recientemente se ha vinculado esta representación con el modelo de la Sibila Samia, de colección particular en Francia, de hacia 1640 - 1650, atribuida al obrador zurbaranesco por Navarrete Prieto, siguiendo los modelos grabados de Pierre de Jode y de Vignon?

La última pintura de este testero nos muestra la presencia de perfil, mirando al frente, del arcángel San Gabriel, también con curiosa iconografía, portando un libro en la mano derecha. La zona inferior del lienzo también está añadida. Presenta una inscripción superior derecha que dice: "Ecce vir Gabriel."; Aquel varón Gabriel. En la zona inferior, a los pies del arcángel: "Daniel, nunc egressus sum ut docerem te. (Dan. 9. v. 21. v. 22)"; Daniel vengo ahora para hacerte entender. (Daniel 9, 22). A pesar del mal estado de conservación y repintes que presenta este lienzo, su curiosa iconografía le hace singular en el conjunto de la serie de esta capilla de San Miguel, puesto que la presencia de San Gabriel se repite en tres ocasiones.

Las representaciones del testero de la derecha comienzan en la parte superior izquierda con la de un Ángel que en perspectiva de tres cuartos desenvaina una gran espada. La inscripción que figura a sus pies, seguramente posterior, aclara su iconografía: "Venit angelus Domini, et percussit in castris As(s)yriorum 158D. (4. Reg 19. v. 35.)"; Vino el ángel del Señor e hirió en el campamento de los asirios a ciento ochenta y cinco mil. (2 Reyes 19,35). Esta curiosa iconografía nos presenta una variante de la representación de los ángeles y arcángeles hasta ahora identificados con el arcángel Uriel o con la de Raziel o Peliel, el ángel que expulsa a Adán y Eva del Paraiso. La valiente concepción de la figura de este Ángel, que deja ver buena parte de su cuerpo, su mayor sentido dinámico y poco usual iconografía, hacen original esta pintura. Su presencia puede vincularse con el angélico personaje nominado anteriormente como San Miguel o Raziel o Peliel, en la serie del Hospital del Pozo Santo, con modelo

6. Díaz Padrón, Matías, "Arte de los siglos XVI al XVIII", en Colección Banco Hispano Americano, Madrid, 1991, p. 40.

7. Navarrete Prieto, Benito, "Génesis y descendencia de Las doce tribus de Israel y otras series zurbaranescas", en el Catálogo de la Exposición: Zurbarán. Las doce tribus de Israel, Madrid, 1995, pp. 65 y 66. 
iconográfico diferente, pues envaina una espada típica del siglo XVII ${ }^{8}$. Esta iconografía fue denominada Arcángel Hadriel en la citada serie limeña.

A la derecha de esta última pintura aparece una figura que en principio podría vincularse con el arcángel Uriel, el "Fortis Socius" veterotestamentario que ayuda a Esdras. Este arcángel, no canónico, y por lo tanto sin la inscripción de su nombre en el lienzo, es pintado en movimiento, en perspectiva de tres cuartos, y con la espada flameante en su mano derecha. De esta manera es representado en los grabados del siglo XVI. Sin embargo, en la parte superior del lienzo figura la inscripción: "Et col(l)ocavit, ante Paradisum (voluptatis) cherubim, et flam(m)eu(m) gladium. (Gen. 3 v. 24)"; Colocó delante del Paraíso un querubín que blandía espada flameante. ( Génesis 3, 24). Por ello esta pintura puede ser identificada con la imagen del Ángel Raziel, que expulsa a Adán y Eva del Paraíso, siguiendo el mismo modelo, aunque con menor riqueza en la vestimenta y postura física contraria, del Ángel Raziel, que figura en la serie del convento de la Concepción de Lima.

En el lienzo central de este testero aparece nuevamente San Gabriel. Muestra al arcángel de frente, en actitud humilde propia de la Anunciación, portando la bara de azucenas que identifica claramente su iconografía. La inscripción superior lo confirma: "Missus est angelus Gabriel. (S. Lu. 1. v. 26.)"; Fue enviado el ángel Gabriel (Lucas 1, 26). Efectivamente se confirma con ello la presencia de la imagen del "Nuntius", es decir la tradicional de Gabriel anunciador de María. En la serie sevillana del Hospital del Pozo Santo, aunque con menor calidad artística, se repite exactamente el mismo modelo, con la diferencia de portar una rama de olivo, por lo que en su momento identificamos aquella imagen con el arcángel Seatiel, conocido como el "Orator". Seatiel, el arcángel que evita el sacrificio de Isaac, porta la rama de olivo como símbolo de paz entre Dios y los hombres ${ }^{9}$. En la serie limeña del convento de la Concepción, el atributo de la rama de olivo es portado por Uriel, el instructor de Esdras, tal y como aparece pintado en la zona inferior derecha de ese lienzo, aunque el modelo es copia del grabado de Crispín de Passe que representa al arcángel Gabriel, mal citado con anterioridad como Ariel ${ }^{10}$.

La zona baja presenta en primer lugar la representación nuevamente de San Rafael, en la tradicional iconografía de este arcángel, con hábito de peregrino, portando el báculo en la mano izquierda y el pez con la derecha; con cuya hiel Tobías curaría la ceguera de su padre. La inscripción de la parte superior derecha: "S. Rafael, medicina Dei; confirma el carácter de Rafael como el "Curator" del bíblico Libro de Tobías. Esta inscripción se repite en muchas de las series arcangélicas en la pintura española, formadas, tradicionalmente, por siete arcángeles; cantidad que el propio San Rafael confirma en el Libro de Tobias (12, 15): "Ego enim sum Raphael angelus, unus ex septen, qui adstamus ante Dominum"; Yo soy Rafael, uno

8. Fernández López, José, ob. cit., lám. $\mathbf{n}^{\circ} 35$.

9. Fernández López, José, ob. cit., p. 134.

10. Valdivieso, E., ob. cit., p. 44. 
de los siete ángeles que nos presentamos ante el Señor. La parte inferior de este lienzo es un añadido. El mismo modelo, de entidad artística inferior, se repite en la serie sevillana del Hospital del Pozo Santo. Totalmente diferente es el modelo de San Rafael limeño.

La última pintura de esta serie representa de nuevo al arcángel San Gabriel, en ligera perspectiva, actitud anunciadora, portando un gran libro en la mano izquierda. La inscripción inferior, que nos ofrece alguna duda sobre su autenticidad, reza: "Ego sum Gabrie(l). Et missus sum loqu(i) ad te ¿(Zacharâ)? et haec tibi evangelizare. S. Luc. 1. v. 19."; Yo soy Gabriel..., y he sido a ti para comunicarte la buena nueva. (Lucas 1, 19). Gabriel, el arcángel conocido como "la fuerza de Dios", aparece en el Antiguo y en el Nuevo Testamento en misión de nuncio o enviado. En su iconografía habitual aparece anunciando la venida de Cristo. Es excepcional, como ocurre en este caso, su imagen anunciando a Zacarías el nacimiento del Precursor, San Juan Bautista.

La serie de ángeles y arcángeles de la capilla de San Miguel de la catedral de Jaén participa, por su filiación y datación artística, de las características de la escuela pictórica sevillana del comedio del siglo XVII y también, por lo tanto, de la polémica cuestión del estudio de sus personalidades artísticas menores en ese período. Estos pintores, muchos de ellos autores de una interesante producción, fueron profundamente influidos por Zurbarán y la producción salida de su taller, llegándoles a impactar, incluso, la actividad del primer Murillo. Su trabajo se viene situando tradicionalmente entre 1640 y 1650 . Efectivamente la influencia zurbaranesca en ellos resulta clara, aunque el pintor o los pintores de la serie jiennense parecen haber alcanzado un estilo propio, basándose en modelos comunes a toda la escuela. El dibujo correcto aunque blando que presentan estos lienzos, el sentido de monumentalidad de sus figuras y su colorido, nos hace reflexionar sobre su proximidad a la actividad del taller de algunos pintores sevillanos de aquel momento. Pero el campo de las hipótesis en la Historia de la Pintura es sumamente resbaladizo, por lo que sólo en el futuro se podría emitir, tras un mejor conocimiento atributivo y documental, dictámenes de mayor justeza. Sí podemos en este caso señalar un hecho documental conocido. En el testamento e inventario de Francisco Polanco, uno de los pintores más interesantes de este período, se citan: "doce cuadros de ángeles de a dos varas cada uno" ". Por lo tanto este pintor, como otros sevillanos, realizaron series angélicas con lienzos de considerables dimensiones.

No fue Sevilla, sin embargo, el lugar donde surgió este tipo de representaciones, que fueron conocidas en la escuela a través de grabados, fundamentalmente flamencos, de fines del siglo XVI y principios del XVII. Sabemos que pintores como Martín de Vos dibujaron ángeles, grabados por Crispin de Passe, Gerhard de Jode y Thomas de Leu. Estas imágenes fueron más tarde modelos para los pintores del

11. Cuellar Contreras, Francisco de P., "Testamento e inventario de francisco Polanco", en Revista de Arte sevillano, $\mathrm{n}^{\circ} 1,1982$ p. 41. 
siglo XVII español ${ }^{12}$. Incluso, como hemos visto, se utilizaron los modelos grabados de sibilas, adaptándolas a la iconografía de los arcángeles. Otras fuentes iconográficas fueron también de gran influencia en la creación de series arcangélicas como los repertorios grabados de Jerónimo Wierix y Philipp Galle. A pesar de todo esto, los arcángeles y ángeles de origen sevillano de mediados del siglo XVII gozaron de una indudable personalidad y originalidad iconográfica por su simplicidad compositiva, su majestuosidad, riqueza suntuaria y plasticidad, que si en ocasiones resulta hierática, habitualmente es solemne. No olvidemos, por último, el carácter religioso sencillo y amable de este tipo de representaciones, adecuado especialmente a la piedad de los cenobios femeninos; ya que, como indican las fuentes iconológicas, las figuras angélicas eran protectoras de los dones o bienes espirituales de la comunidad.

12. Valdivieso, E., Ob. cit., p. 35. 


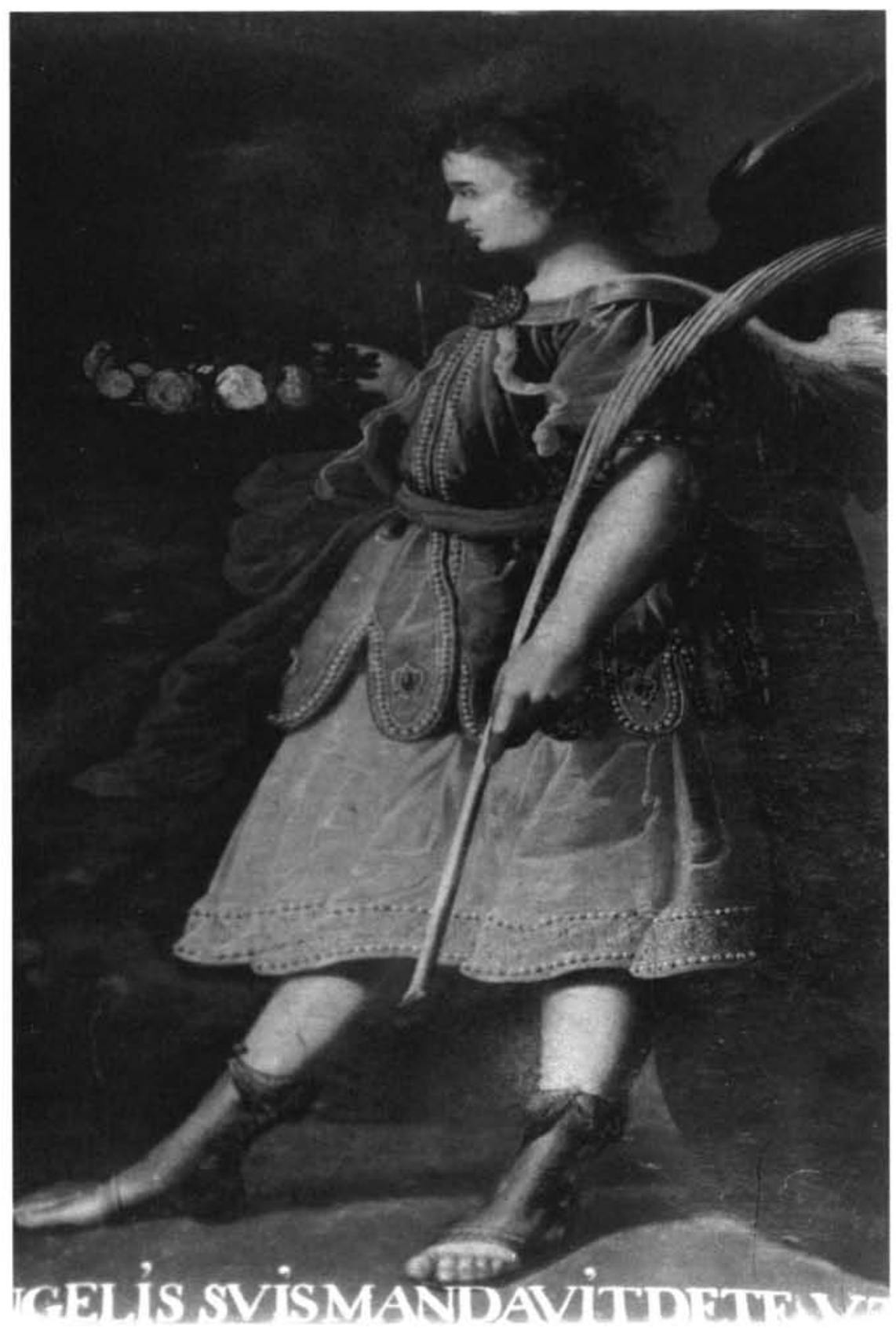

Fig. 1

Baraquiel. Jaén. Catedral. Capilla de San Miguel. 


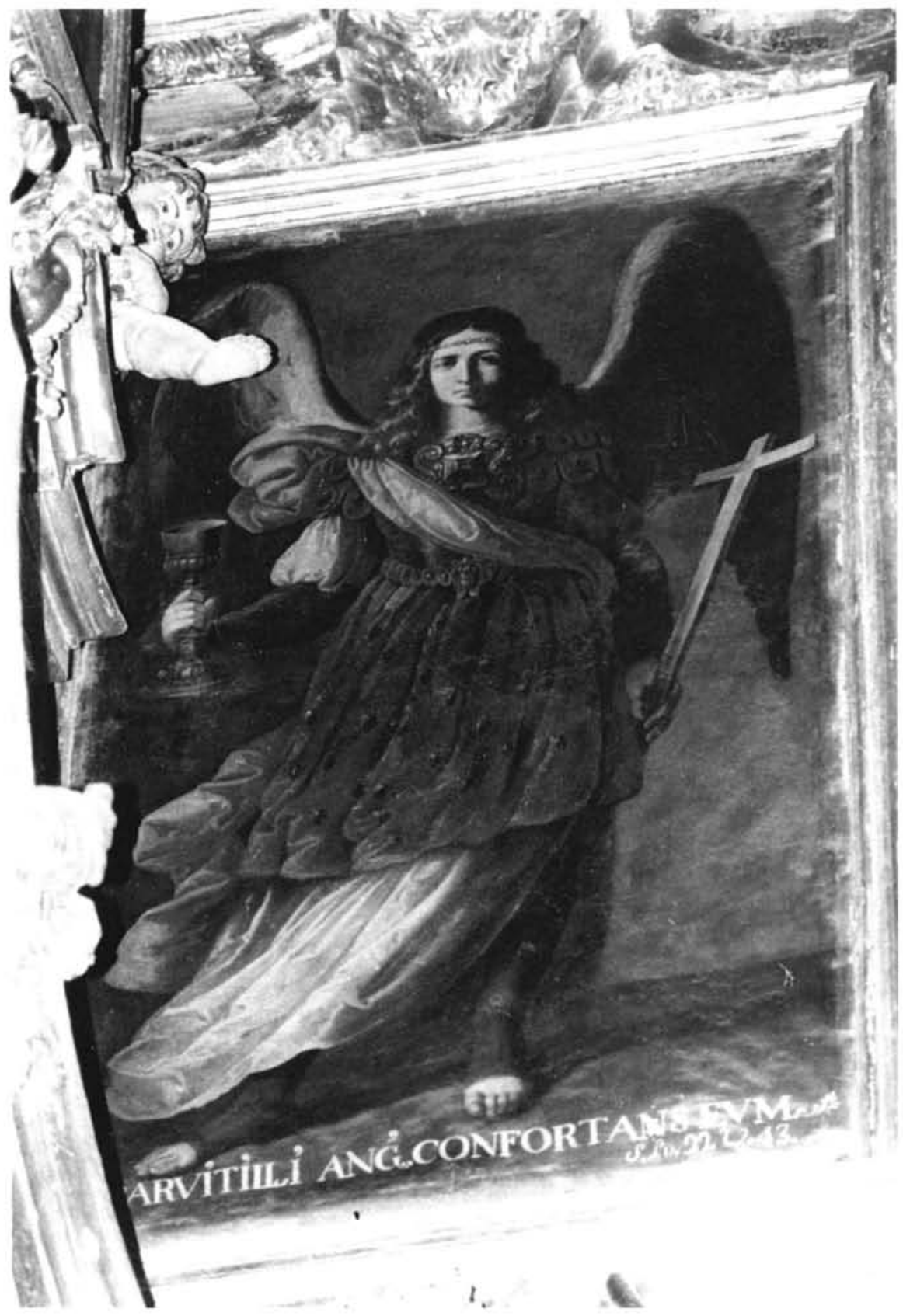

Fig. 2

Ángel de Getsemaní. Jaén. Catedral. Capilla de San Miguel. 


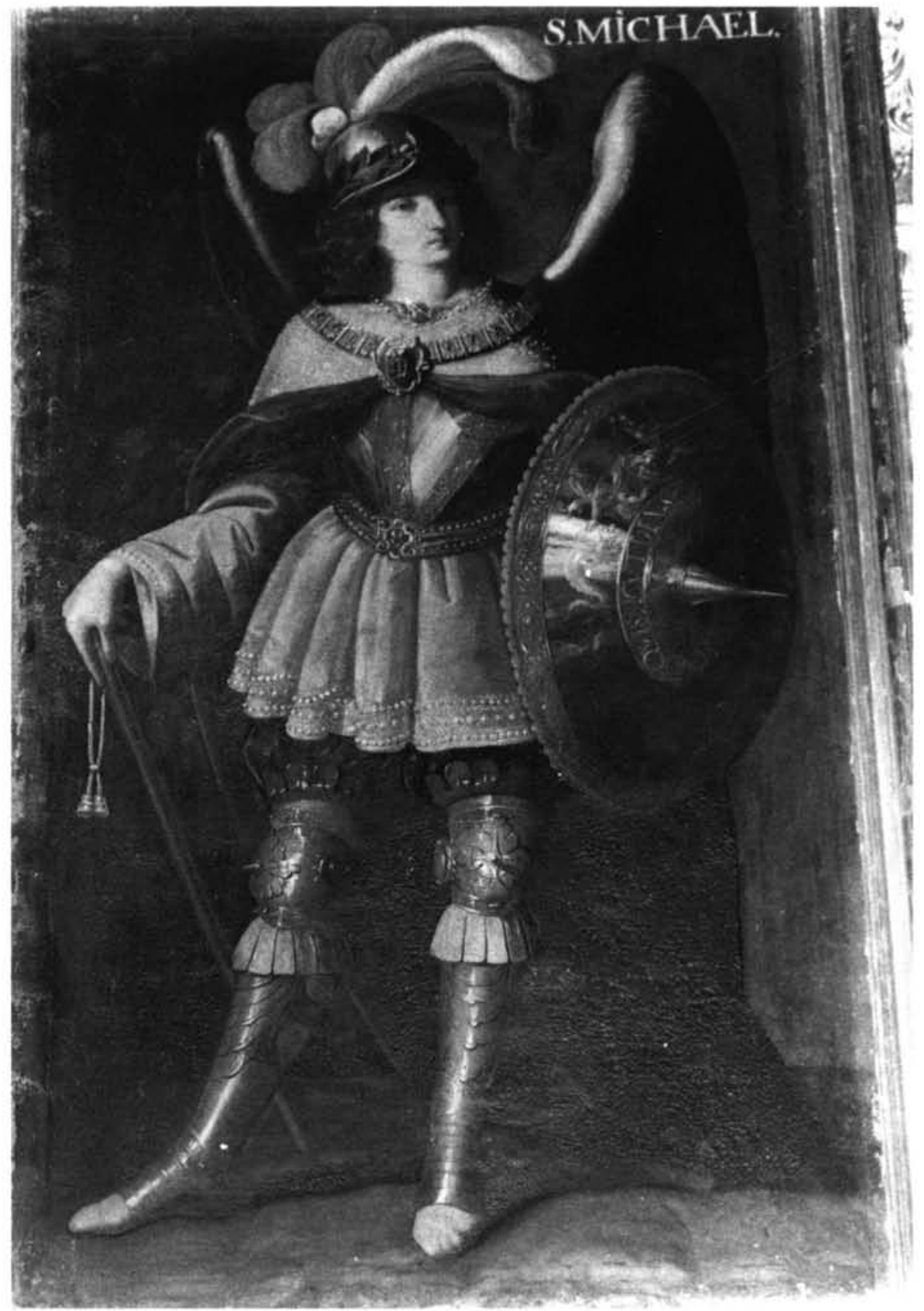

Fig. 3

San Miguel. Jaén. Catedral. Capilla de San Miguel. 


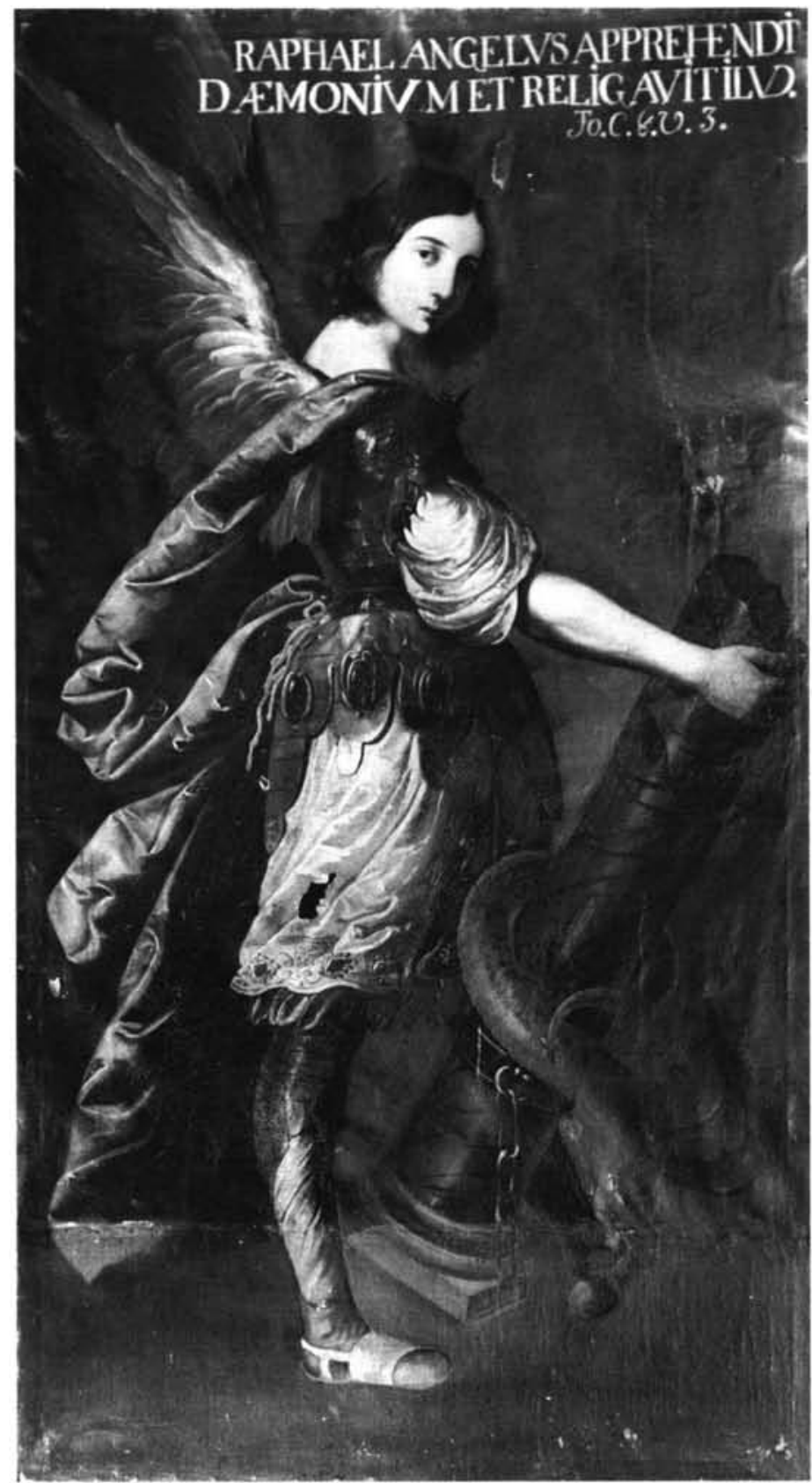

Fig. 4

San Rafael. Jaén. Catedral. Capilla de San Miguel. 


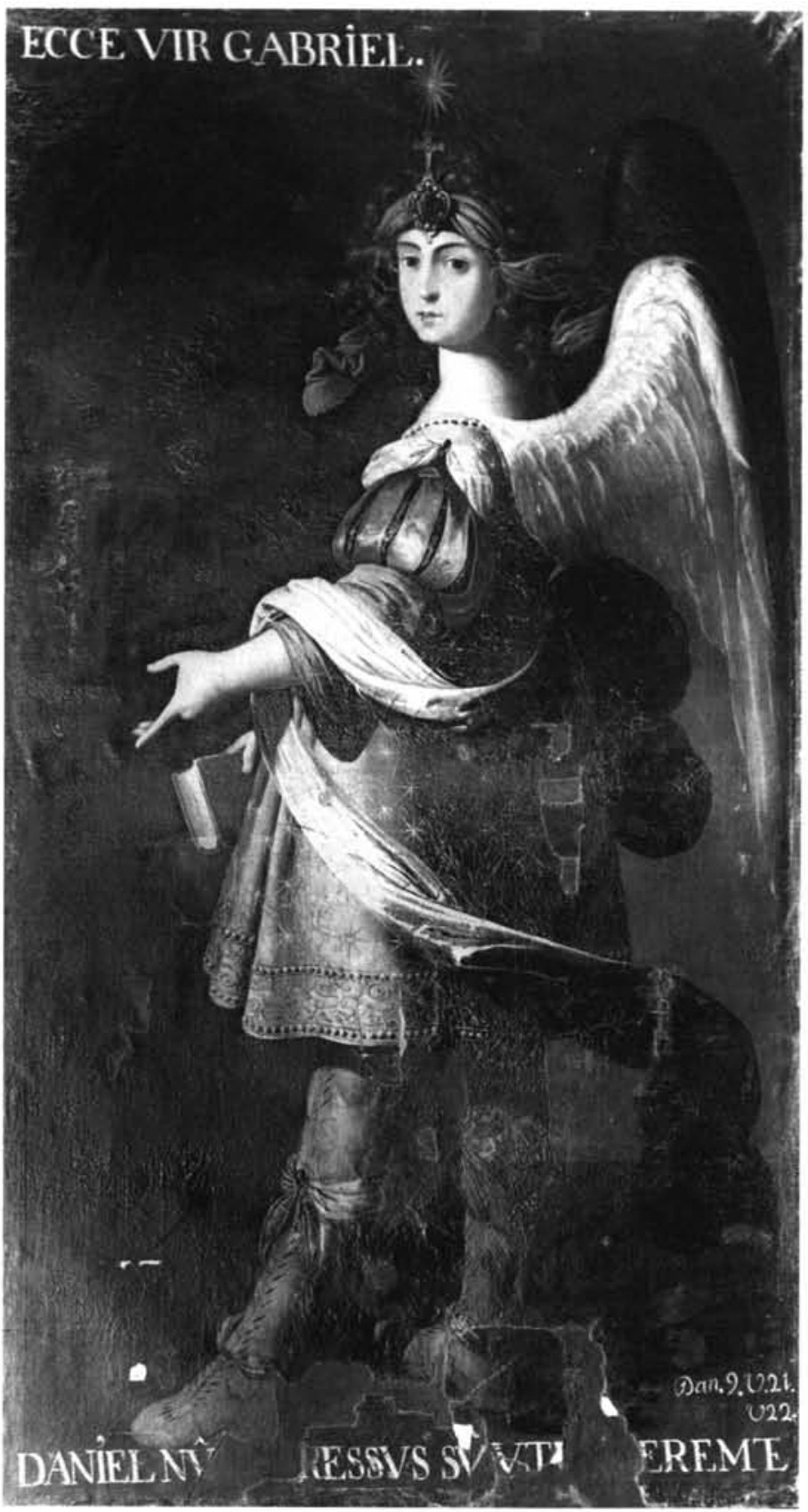

Fig. 5

San Gabriel. Jaén. Catedral. Capilla de San Miguel. 


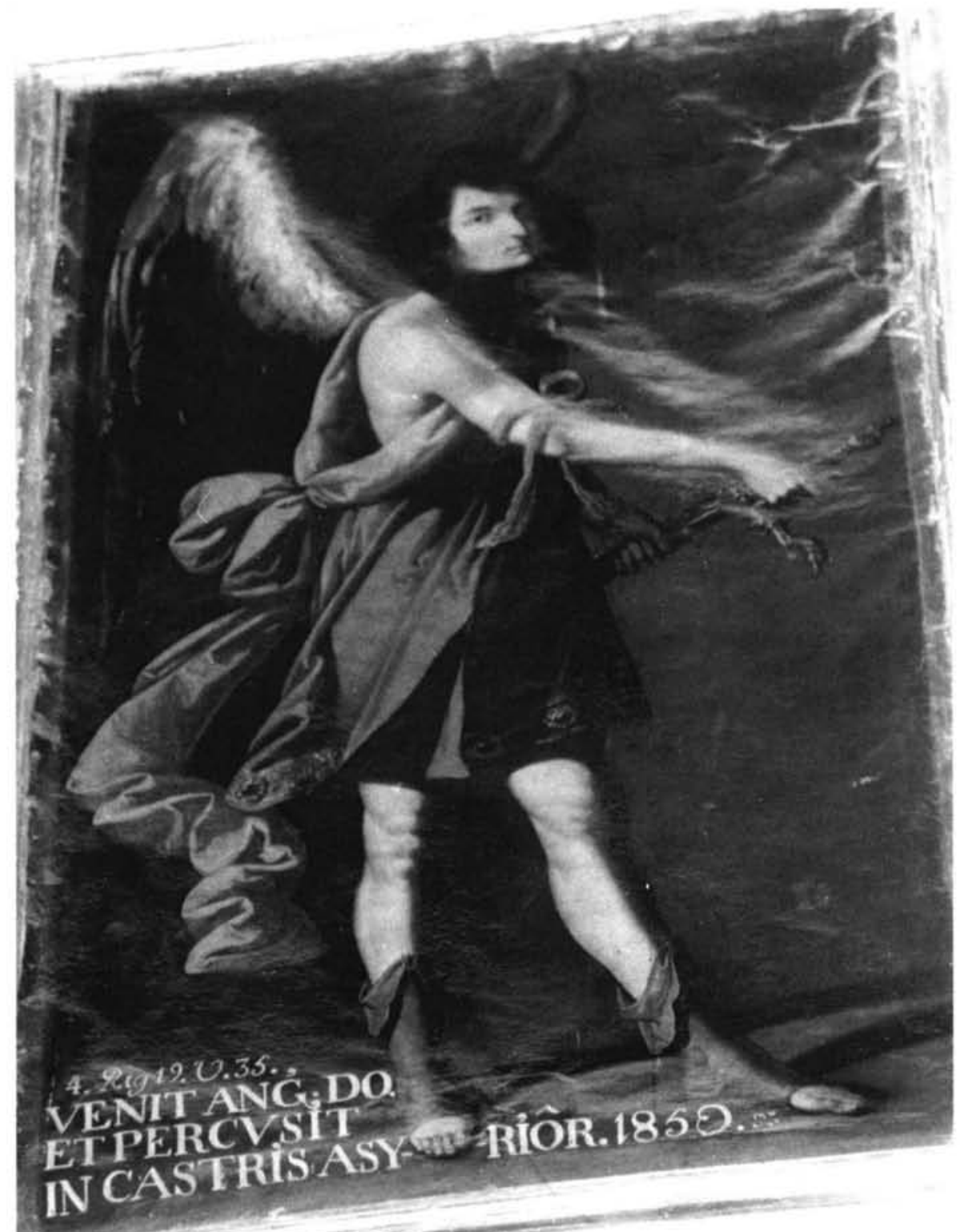

Fig. 6

Ángel. Jaén. Catedral. Capilla de San Miguel. 


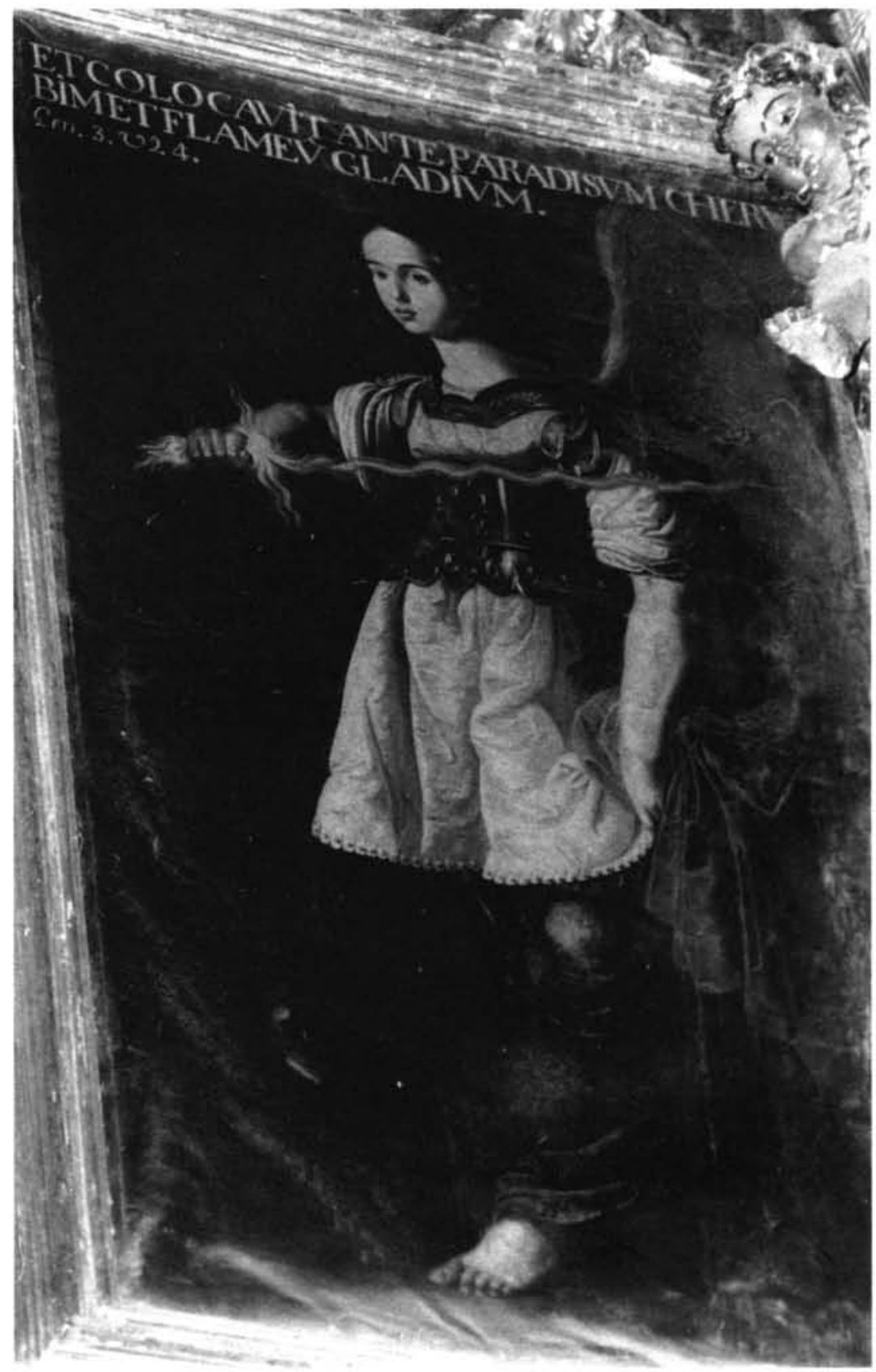

Fig. 7

Raziel. Jaén. Catedral. Capilla de San Miguel. 


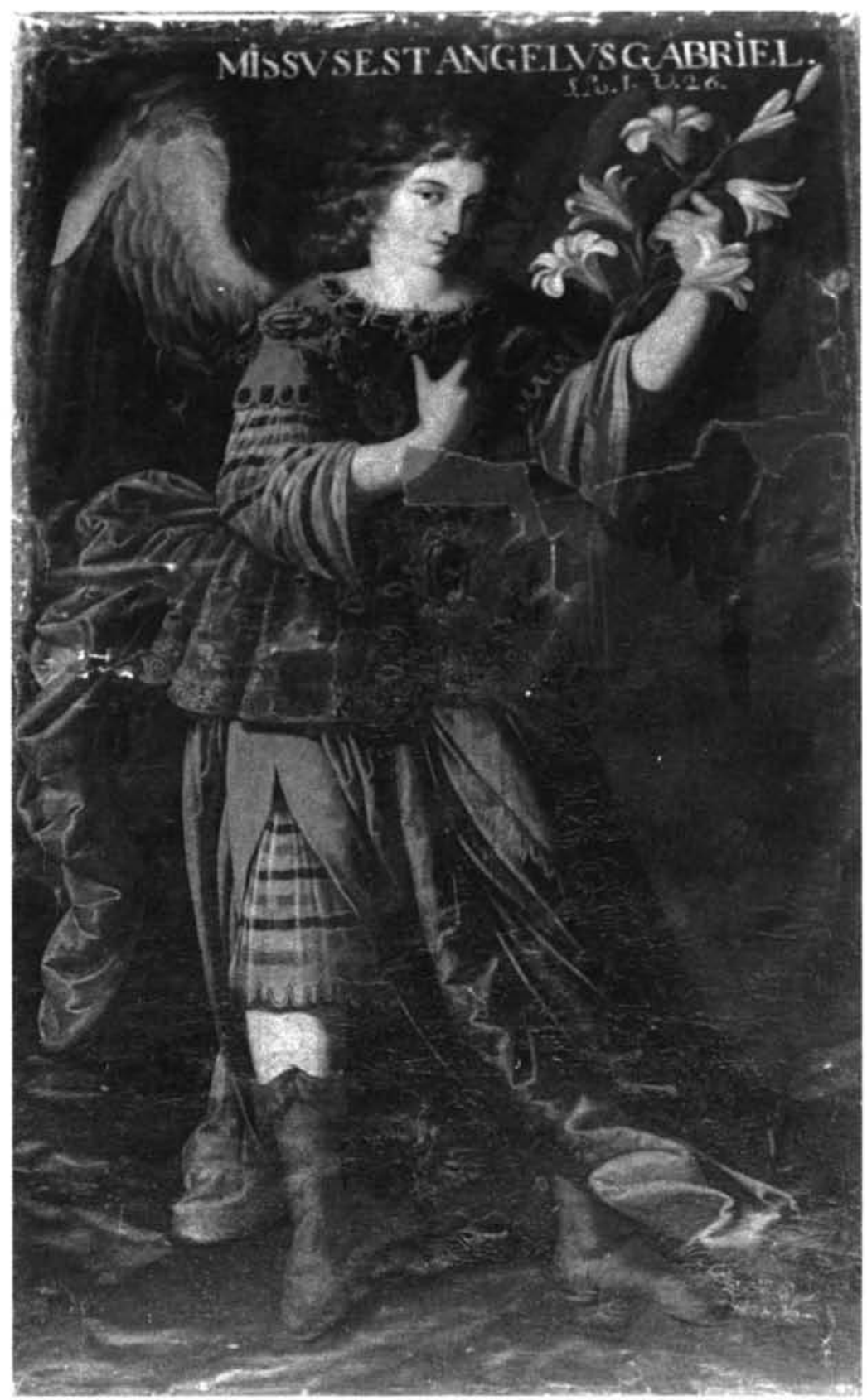

Fig. 8

San Gabriel. Jaén. Catedral. Capilla de San Miguel. 


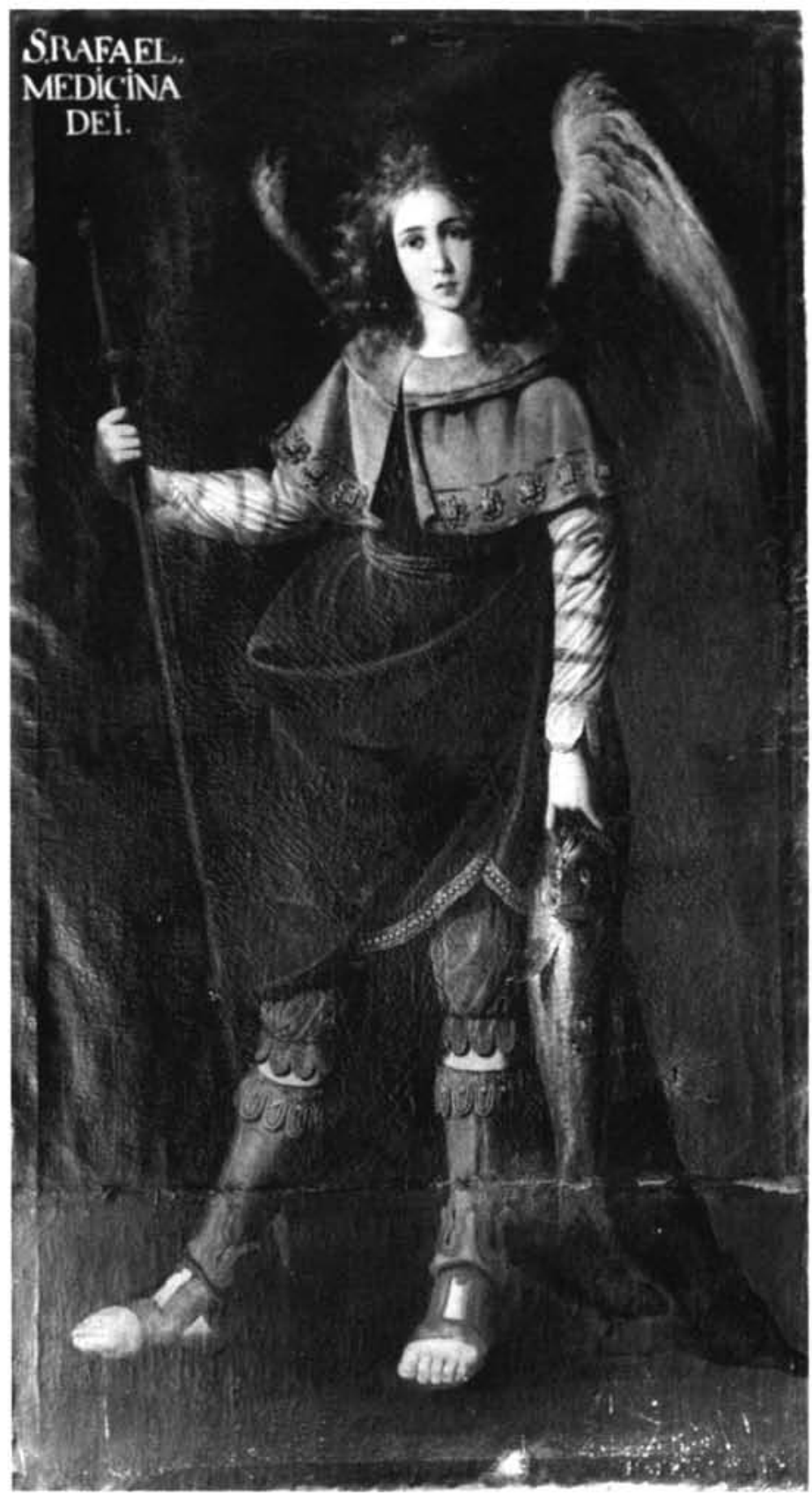

Fig. 9

San Rafael. Jaén. Catedral. Capilla de San Miguel. 


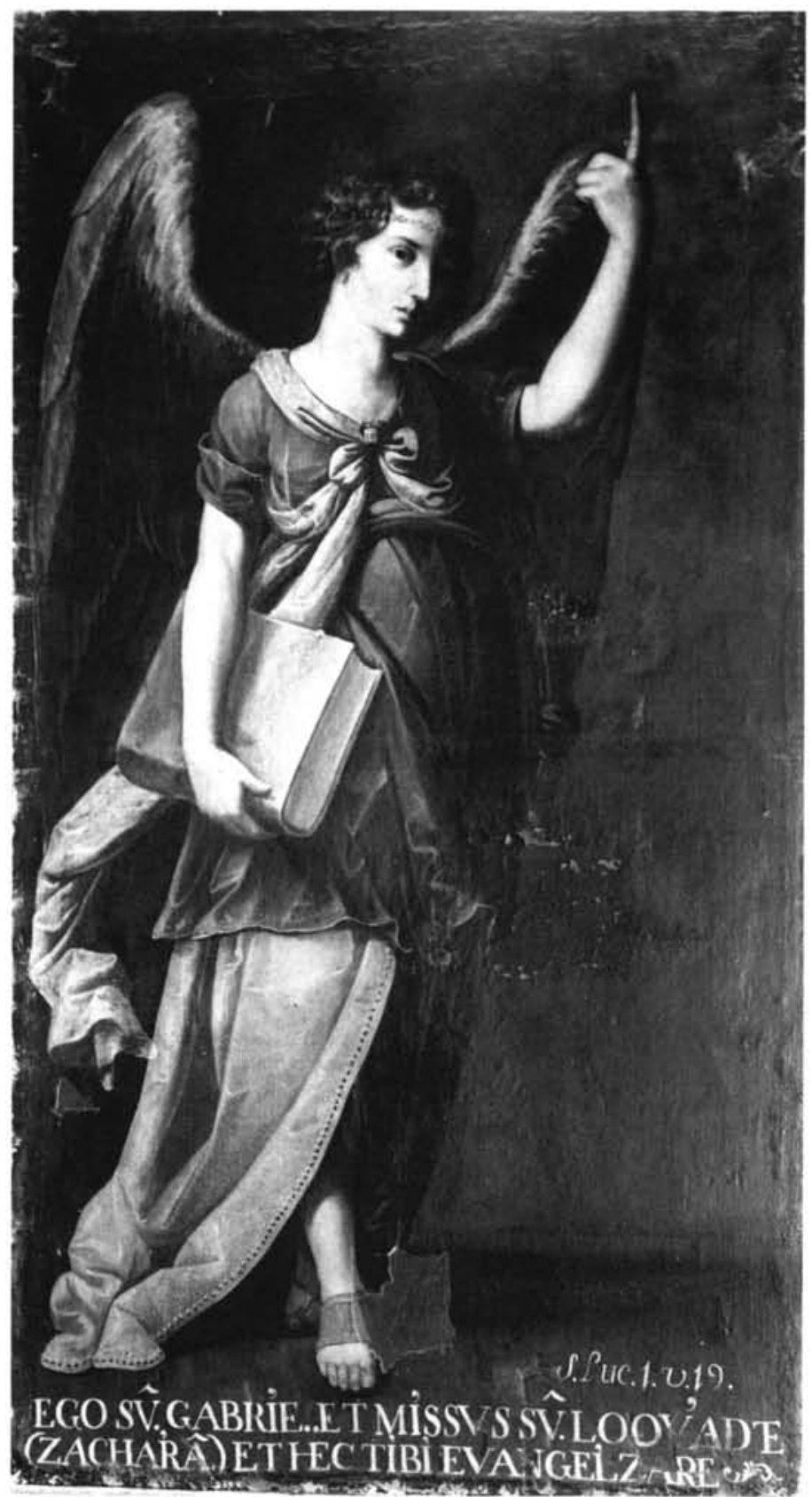

Fig. 10

San Gabriel. Jaén. Catedral. Capilla de San Miguel. 